\title{
Low Grade Vaginal Intraepithelial Neoplasia
}

National Cancer Institute

\section{Source}

National Cancer Institute. Low Grade Vaginal Intraepithelial Neoplasia. NCI Thesaurus.

Code $C 4644$.

Vaginal intraepithelial neoplasia characterized by the presence of koilocytosis and disorganization and thickening of the basal layer. 